\title{
ESTRATÉGIAS DE APROPRIAÇÃO TERRITORIAL NA CULTURA TRADICIONAL DOS INDÍGENAS SURUÍ EM RONDÔNIA-BRASIL EM TEMPOS DE COVID-19
}

\author{
GIOVANA GORETTI FEIJÓ DE ALMEIDA ${ }^{1}$ \\ CiTUR, LEIRIA, PORTUGAL \\ https://orcid.org/0000-0003-0956-1341 \\ EDSON MODESTO DE ARAÚJO JÚNIOR ${ }^{2}$ \\ UNIR, BRASIL \\ https://orcid.org/0000-0002-1366-0273
}

\begin{abstract}
RESUMO: As invasões em terras indígenas continuam mesmo durante a pandemia de Covid-19. O objetivo é compreender as estratégias de apropriação territorial em terras de culturas tradicionais, como a dos indígenas Suruí, em Rondônia, Brasil. A metodologia da pesquisa utilizou o método de estudo de caso com abordagem qualitativa, valendo-se de um protocolo de pesquisa com três variáveis. Os resultados apontaram para um conjunto de diferentes tipos de invasores de terras indigenas, que não mais se resumem apenas aos latifundiários, podendo a pandemia do coronavírus ter contribuído para o aumento das invasões. A conclusão reitera que as estratégias de apropriação territorial em terras indígenas foram ampliadas, dando indícios da existência de um processo de apagamento da identidade territorial dos indígenas na América Latina.
\end{abstract}

PALAVRAS-CHAVE: Covid-19, cultura tradicional, apropriação territorial, territorialização, territorialidades.

\begin{abstract}
Invasions into indigenous lands continuous even during the Covid-19 pandemic. The objective is to understand the strategies of territorial appropriation in lands of traditional cultures, such as that of the Surui Indigenous, in Rondonia, Brazil. The research methodology used the case study method with a qualitative approach using a research protocol with three variables. The results pointed to a set of different types of invaders of indigenous lands, which are no longer limited to landowners, and the coronavirus pandemic may have contributed to this increase in invasions. The conclusion reiterates that the strategies of territorial appropriation in indigenous lands have been expanded, giving evidence of the existence of a process of erasing the territorial identity of the indigenous in Latin America.
\end{abstract}

KEYWORDS: Covid-19, traditional culture, territorial appropriation, territorialization, territorialities.

\footnotetext{
${ }^{1}$ Doutora em Desenvolvimento Regional (UNISC). Pesquisadora integrada ao Centre for Tourism Research, Development, and Innovation (CiTUR), Leiria, Portugal. E-mail: goretti.giovana@gmail.com

${ }^{2}$ Doutor em Desenvolvimento Regional (UNISC). Professor Adjunto permanente na Universidade Federal de Rondônia (UNIR). E-mail: modesto@unir.br

ALMEIDA, Giovana Goretti Feijó de; ARAÚJO JÚNIOR, Edson Modesto de. Estratégias de apropriação territorial na cultura tradicional dos indígenas Suruí em Rondônia-Brasil em tempos de Covid-19. Espaço Ameríndio, Porto Alegre, v. 15, n. 3, p. 71-90, set./dez. 2021.
} 


\section{Introdução}

A pandemia de Covid-19 é uma realidade mundial e no contexto das culturas tradicionais não é diferente. Contudo, em terras em que há maiores disputas, como a dos indígenas, a situação pode se tornar mais agravante quando agregada ao desmatamento, invasões, incêndios florestais e à própria progressão da pandemia em comunidades vulneráveis. Não se trata apenas da invasão de garimpeiros, mas de invasões de madeireiros, empresas petroleiras, caçadores ilegais e narcotraficantes. As hidrelétricas, por exemplo, podem ser uma ameaça à vida, às territorialidades e aos direitos de populações indígenas, impondo que essas culturas tradicionais tenham que se articular politicamente na busca por seus direitos (Nascimento Silva, 2018). São situações críticas que podem levar ao genocídio dos povos indígenas isolados, como os do Vale do Javari, no Estado do Amazonas (WM, 2010; ISA, 2018) ou os Suruí, no Estado de Rondônia, Brasil.

Ressalta-se que os povos indígenas de diversos países da América Latina têm relatado situações semelhantes (ISA, 2018). Estima-se que cerca de $90 \%$ da violência contra ativistas de terras indígenas está concentrada na Amazônia (Global Witness, 2020). No Estado do Maranhão, Brasil, algumas comunidades indígenas têm se utilizado dos guardiões da floresta. São grupos de agentes ambientais formados pelos próprios indígenas para autodefesa de seus territórios. Na luta contra os invasores de suas terras, muitos desses guardiões têm sido assassinados. Salienta-se que, na Amazônia, cerca de $80 \%$ da floresta amazônica já foi devastada (Brasil de Fato, 2020), levando também ao apagamento da identidade territorial das etnias indígenas, narrativas e história, ampliando sua exclusão na sociedade.

Tratam-se de situações que absorvem uma pluralidade de dimensões e a migração forçada dos indígenas (Osorio Campillo, 2015; Preciado Trujillo, 2017); (in)visibilidade do indígena no espaço urbano (Radicchi, 2020) e as distintas formas em que o indígena é obrigado a transformar seu modo de vida (Maréchal et al., 2020). No século vigente, além de passar sua cultura de geração em geração, as comunidades indígenas estão inseridas numa luta coletiva pela reivindicação de seus direitos como cidadãos, domínio das terras de seus antepassados, reconhecimento identitário de sua cultura (Maréchal et al., 2020) e transformação de sua cultura tradicional (Perius, 2020), obrigando-Ihes também a aderir a uma espécie de cultura indígena urbanizada. Neste tipo de cultura híbrida, entre tradicional e urbana, a Covid-19 impõe medidas de saúde Ocidentais, como a vacinação em massa. Nem todos os indígenas querem a vacinação porque não faz parte de seu ritual e de suas crenças que envolvem a saúde de suas comunidades, como foi o caso dos indígenas situados em Estrela Velha (Dotto, 2021).

Os problemas da pesquisa envolvem a configuração de espacialidades sobrepostas às projeções econômicas (Siegert et al., 2018); deslocamentos forçados de indígenas (Osorio Campillo, 2015; Preciado Trujillo, 2017); conflitos originados do ordenamento territorial (Torres Tovar, 2016; 
Espaço Ameríndio

(Fernández-Labbé, 2020); influência das classes dominantes (Bustamante Patiño; Herrero Olarte, 2017); transformações do território e as outras territorialidades advindas de processos migratórios (Osorio Campillo, 2015); concepção do território como campo de renda a partir da lógica capitalista do extrativismo (Ramirez, 2016; García-Jerez, 2019); áreas estratégicas para o desenvolvimento da economia de enclaves (García Gualda, 2021); apropriação associada à territorialização e urbanização (Nicoletti; Núñez, 2019); habitabilidade e assentamentos indígenas em áreas de alto risco (Vázquez-Honorato et al., 2019); proliferação de lutas por território em comunidades tradicionais (Guedes, 2016); processos de territorialização no entendimento sobre como os territórios se constroem historicamente (Tamagno; Maidana, 201 1); diferenças entre mundo indígena e não-indígena (Menezes et. al., 2020); e a importância da ressignificação simbólica e valorização de relatos históricos indígenas (Santos et. al., 2020).

A questão-problema enfatiza: Quais estratégias têm sido utilizadas na apropriação territorial em terras de culturas tradicionais, como a dos índios Suruí, em Rondônia, Brasil, durante a pandemia Covid-19?

O objetivo é compreender quais estratégias têm sido utilizadas na apropriação territorial em terras de culturas tradicionais, como a dos índios Suruí, em Rondônia, Brasil, durante a pandemia Covid-19. Aprofunda-se o entendimento sobre o lugar da cultura tradicional e do pluralismo cultural na sociedade contemporânea como um indicador de bem-estar da sociedade (Carvalho, 1989).

As justificativas da pesquisa englobam insuficiência de economias de países do terceiro mundo quanto ao desenvolvimento de paradigmas de modelos econômicos (Montero Graniela, 2021); territorialização da memória na valorização da cidadania e memória coletiva (Rodríguez et al., 2019); direito territorial no contexto dos conflitos legais ou ilegais (Calderón, 2015); estendendo-se às experiências vivenciadas por comunidades que no território fortalecem suas relações etnoterritoriais (Marcilino; Tomaz, 2020); e a importância das políticas públicas para os indígenas (Luciano et al., 2020).

\section{Fundamentação teórica}

\section{Território e territorialidades}

O conceito de território está galgado nas contradições em múltiplas dimensões, compreendendo-o como delimitação das relações de poder dos atores sociais (Raffestin, 1993); espaço de luta e resistência numa perspectiva intercultural (Marcilino; Tomaz, 2020); e como uma forma social (Guedes, 2016). Além disso, o território também é um “[...] componente fundamental do desenvolvimento de base local, cultural e ecológica, [...] e na ativação de territorialidades voltadas para a [...] a resistência política 
Espaço Ameríndio

diante das forças hegemônicas do capital e do Estado [...] (Saquet, 2018, p. $1)$.

Essas discussões levam à articulação dos atores sociais, gerando embates físicos ou simbólicos. Um desses embates pode se valer da marca territorial como estratégia de disputas territoriais, utilizando estratagemas comuns ao universo das marcas mercadológicas. As marcas territoriais demarcam um território simbólico por meio de sinais distintivos e discursivos, podendo também remeter ao território físico. A persuasão do confronto se dá no nível simbólico, no reconhecimento de um dado espaço produzido coletivamente (Almeida, 2018). O reconhecimento do território e das territorialidades dos atores sociais ocorre na fluidez de um discurso planejado que "[...] naturaliza os interesses implícitos dos atores, influenciando nas representações, identidades e relações de poder do e no território" (Almeida, 2018, p. 37).

Os debates com as culturas tradicionais levam às dialéticas: dominador e dominado, cultura hegemônica e contra hegemônica, passado e presente, tradição e modernidade, local e global, memórias e aprendizagens; com forma de condicionar a vida urbana à cultura tradicional (Tamagno; Maidana, 2011). Essas dialéticas são também formas de conflito simbólico entre as culturas de modo a ativar ou desativar as territorialidades centradas na resistência às forças hegemônicas (Saquet, 2018).

Territorialidade remete à recriação da realidade dos atores sociais a partir de suas vivências e memórias (Ozouf, 1976), incorporando-se às dimensões política, econômica e cultural. Essas dimensões estão ligadas ao modo como as pessoas usam e se apropriam do território produzido. A forma como se dá essa organização no espaço e significado ao lugar é chamado de territorialidade (Haesbaert, 1999), remetendo a uma disputa de forças físicas e simbólicas. Neste contexto de apropriação do território está inserido ainda o conceito de unidade de significação territorial que se dirige à criação e apropriação simbólica do indivíduo que durante uma experiência no território movimenta as estruturas sociais, espaciais e temporais, permitindo a construção e interpretação do mundo, tornando-se um suporte para a inserção socio-relacional (pertencimento do sujeito) e socioespacial (pertencente a um território), baseado num processo de territorialização provisória. As unidades de significação territorial se tornam um elementochave para a compreensão das várias formas com que os sujeitos estabelecem suas narrativas para a apropriação simbólico-material dos territórios (Araujo Júnior, 2020).

\section{Culturas tradicionais e conflitos territoriais}

A forma ancestral de produzir conhecimento se refere a um aparato cognitivo complexo que envolve técnicas de manejo de recursos naturais, métodos de caça e pesca, conhecimentos sobre a diversidade de ecossistemas existentes e processos agrícolas rudimentares utilizados por

ALMEIDA, Giovana Goretti Feijó de; ARAÚJO JÚNIOR, Edson Modesto de. Estratégias de apropriação territorial na cultura tradicional dos indígenas Suruí em Rondônia-Brasil em tempos de Covid-19. Espaço Ameríndio, Porto Alegre, v. 15, n. 3, p. 71-90, set./dez. 2021. 
populações tradicionais (Santilli, 2005; Almeida, 2004). É um conhecimento popular que vai além do uso de ervas medicinais, remetendo à dimensão simbólica de rituais e da vida social em grupo (Lévi-Strauss, 1976; Castro, 2000) para preservar uma cultura.

Não há uma definição universal para populações tradicionais, sendo recorrente associá-las às comunidades indígenas, romanis, quilombolas, ribeirinhos, caiçaras, caboclos, jangadeiros e outras. Há várias nomenclaturas utilizadas, tais como: comunidades locais, povos indígenas, comunidade indígena, comunidade local, populações tradicionais, sociedades tradicionais, comunidades tradicionais, povos tradicionais, dentre outras. O cenário traçado revela que a terminologia é ampla e não está ainda definida (Diegues, 1998; Castro, 2000; Cunha; Almeida, 2004). Desta forma, optou-se por utilizar o termo cultura tradicional para se referir a comunidades específicas, como os indígenas. Segundo Castro (2000, p. 165), as culturas ou populações tradicionais se dirigem às "[...] populações que vivem em estreita relação com o ambiente natural, dependendo de seus recursos naturais para sua reprodução sociocultural".

Compreende-se por conflito territorial as questões espaciais envolvidas numa disputa de poder pelo uso ou apropriação de determinado território. Os conflitos são originados por diferentes motivos, como: independência, questões religiosas, políticas ou econômicas e recursos minerais, remetendo à dimensão geopolítica de conflitos locais. Nesse sentido, os atores sociais empreendem ações e estratégias para dominar o território e impor seus interesses (Leite; Monié, 2014). A tipologia de conflitos territoriais quanto à paisagem, biodiversidade e ambientes, por exemplo, leva ao conflito ambiental. As tensões no acesso, gestão e controle de recursos geram conflitos territoriais que dizem respeito à forma de apropriação do espaço, emergência e reativação de territorialidades (Leite; Monié, 2014). O exposto significa que os conflitos territoriais possuem múltiplas dimensões.

\section{População indígena no Brasil}

A população indígena do Brasil é constituída por comunidades tradicionais diferentes e o direito à diferença cultural está assegurado na Constituição Brasileira (Brasil, 1988, art. 231). Os povos de culturas tradicionais têm direito a se organizarem de forma própria. Para isso, a União assegura esses direitos aos povos tradicionais, zelando por sua cidadania (Domingo; Castedo Maria, 2017).

A cultura indígena carrega mitos advindos da cultura Ocidental, como a dos desbravadores. Ao criá-los, oculta-se o que existia antes da chegada dos colonizadores, mantendo ocultas as riquezas do território e a desapropriação violenta das terras indígenas pela transformação mercantil em ouro e prata e, posteriormente, em produtos agroindustriais (Santos et al., 2020).

ALMEIDA, Giovana Goretti Feijó de; ARAÚjO JÚNIOR, Edson Modesto de. Estratégias de apropriação territorial na cultura tradicional dos indígenas Suruí em Rondônia-Brasil em tempos de Covid-19. Espaço Ameríndio, Porto Alegre, v. 15, n. 3, p. 71-90, set./dez. 2021. 
As culturas tradicionais se referem ao modo de produção précapitalista, em que o trabalho ainda não se converteu em mercadoria, remetendo à produção mercantil para subsistência da comunidade local. 0 manejo dos recursos culturais dessas comunidades não tem o intuito do lucro, mas da reprodução sociocultural de um modo de vida vinculado à natureza e seus ciclos (Diegues, 1998; 2000). A relação dessas comunidades com o território, do qual sobrevivem, possui vínculos físicos e simbólicos demarcados por rituais e crenças passadas de geração para geração (Godelier, 1984). Os indígenas se valem de espaços descontínuos usados em determinadas épocas, como as de colheita e caça, necessários para a vida que levam diariamente.

São características das culturas tradicionais: dependência dos ciclos naturais como modo de vida; manejo estratégico e sustentável dos recursos naturais; transferência oral do conhecimento produzido de geração para geração; território compreendido como extensão da comunidade local; criação de atividades de subsistência rudimentares; importância da hierarquia familiar e de parentesco; importância de simbologias, mitos e rituais associados à natureza; atividades de baixo impacto no meio ambiente; reduzida divisão técnica e social do trabalho, sobressaindo o artesanal; sentimento de pertencimento a uma cultura distinta de outras (Diegues et. al, 2000).

A Constituição Federal Brasileira (Brasil, 1988) reconhece os direitos dos povos indígenas às terras que ocupam (Brasil, 1988, caput art. 231). O reconhecimento brasileiro estende-se ao direito à diferença cultural de culturas tradicionais, incluindo seus direitos coletivos, ao território tradicional, diversidade cultural, patrimônio cultural, ambiente ecologicamente equilibrado e o direito à biodiversidade (Diegues et. al., 2000).

\section{Procedimentos metodológicos}

Utilizou-se o método de estudo de caso, cujas técnicas de pesquisas foram qualitativas nas descrições das variáveis (Yin, 2015). A abrangência da pesquisa contemplou a comunidade indígena dos Suruís, localizada em Rondônia, Brasil.

A unidade de observação da pesquisa considerou:

- Audiovisual da Fundação Nacional do Índio (Funai) "Povos Indígenas: Guardiões da Sustentabilidade" (2018);

- Matérias de jornais locais e;

- Dois sites: 1) Povos indígenas do Brasil - PIB socioambiental (https://pib.socioambiental.org/pt/Povo:Surui_Paiter); e, 2) Kanindé: Associação

de

defesa

etnoambiental 
Espaço Ameríndio

(https://www.kaninde.org.br/indios-surui-apostam-no-mercado-decarbono-para-conservar-terra-em-ro/).

Foi utilizado um protocolo de pesquisa com três variáveis: conflitos territoriais, território/territorialidades e cultura tradicional. A análise dos dados foi comparativa nas variáveis do estudo.

A cultura Suruí de Rondônia foi selecionada para o estudo porque, embora 60\% da área esteja em Mato Grosso, 147.401,73 hectares, existem apenas quatro aldeias no país que representam $9,5 \%$ da população total desses povos indígenas. A disseminação dessas aldeias faz com que a maior parte do relacionamento, tanto comercial quanto social, ocorra no estado de Rondônia, em especial no município de Cacoal, que responde por 84,93\% da população Suruí (CASAI, 2011).

A pesquisa foi realizada de janeiro de 2020 a maio de 2021 .

\section{Análises da pesquisa}

\section{Conflitos entre atores sociais}

À medida que a pandemia Covid-19 se espalhou, a presença de invasores em terras Suruí se ampliou, levando à conflitos territoriais e ambientais. Esses conflitos são disputas de poder em que um determinado grupo de atores sociais anseia pelo uso, apropriação e dominação de um dado território rico em biodiversidade, como o dos Suruís, em Rondônia. A disputa é pelos recursos naturais, remetendo a uma discussão geopolítica e ambiental, cujos conflitos locais envolvem um conjunto de atores sociais: poder privado, poder público, incluindo: alguns setores da sociedade, como o agronegócio e o extrativismo de madeira e ouro. Por esta perspectiva as terras da comunidade Suruí trazem tensões relativas ao uso do solo e à extração de seus recursos naturais. Tem-se uma dominação territorial que diz respeito à imposição dos interesses econômicos dos atores sociais em um espaço que está protegido pela Constituição Federal, mas essa proteção constitucional apresenta lacunas. A dominação em conflitos territoriais tende a não ser passiva, respondendo os dominados, na maioria das vezes, com o confronto físico.

A resposta ao aumento das invasões das terras Suruí atendeu a duas frentes: uma política e outra física. Houve tentativa de organização política dos povos indígenas no envio de uma carta aos órgãos públicos locais que denunciava a invasão de suas terras. Por sua vez, também houve a exigência formal de mais cuidados médicos e efetividade na distribuição de vacinas por parte dos Suruís no reconhecimento das comunidades indígenas como parte do grupo prioritário de vacinas contra o coronavírus. Uma segunda frente foi de ordem física, em que a comunidade Suruí se organizou em grupos, chamados guardiões da sustentabilidade, preparando-se para o confronto físico com os invasores de suas terras. São grupos de proteção e monitoramento de áreas indígenas na tentativa de limitar o aumento de 
invasores, garantindo a proteção da comunidade local. Essas são algumas das estratégias que os atores sociais de ambos os lados têm se utilizado na redefinição de controle territorial de espaços específicos. Um lado avança no ataque (madeireiros, garimpeiros e outros) enquanto o outro lado encontra meios de autodefesa.

Ao mesmo tempo, pode-se dizer que os Suruís enfrentam outro confronto, porém de ordem biológica, em que o coronavírus pode ser um fator decisivo na extinção desta cultura ou até mesmo no apagamento de sua identidade cultural-territorial na medida em que os idosos, ou seja, aqueles que passam a cultura Suruí à nova geração, estão morrendo da pandemia que assola o mundo.

O conflito se estende ainda às esferas local, regional e federal do poder público quando essas discussões são postas em pauta, como: estabelecimento de um sistema de delimitação provisória de áreas centrais indígenas; ao PL 2633/2020 que visa conceder títulos definitivos e anistia aos moradores das áreas de bases de invasão e desmatamento da floresta amazônica; e PL 191/2020 que visa legalizar a mineração em terras indígenas. São medidas que corroboram os interesses econômicos e políticos de um dado conjunto de atores socias em detrimento dos interesses de uma minoria, como a da comunidade dos Suruís.

Desta forma, são dois os principais grupos de atores sociais envolvidos nas discussões das terras dos Suruís: poder privado e poder público (local, regional, federal), estendendo-se às universidades e organizações não-governamentais (nacionais e internacionais) e Funai. Os atores sociais envolvidos na invasão das terras indígenas incluem: madeireiros, setor agronegócio, hidrelétricas, mineradores, extrativistas, garimpeiros, posseiros, biopiratas e caçadores.

\section{Território e territorialidades indígenas}

Todos os territórios, em escala micro ou macro, surgem de alguma disputa, física ou simbólica em que, no mínimo, dois conjuntos de atores sociais pleiteiam um dado espaço, territorializando-o a partir de seus interesses. De um lado há os interesses dos povos indígenas e de outro lado vários atores com distintos interesses nas terras dos Suruís: latifundiários, madeireiros, agronegócios e empresários. A hegemonia nunca é tomada sem tensão, sendo um processo verticalizado e homogêneo (Souza, 2003), em contraste com um processo contra-hegemônico.

Durante anos a cultura do Suruís vem se transformando, delimitandose simbólica e territorialmente nas disputas fronteiriças. Essas transformações causam impacto nas identidades e representações sociais das culturas tradicionais, podendo ser extintas se as invasões continuarem ou se não houver cuidados de saúde neste momento de pandemia de Covid19. O não atendimento aos indígenas como grupo prioritário pode ser visto como uma estratégia consciente ou não de extinção ou apagamento dessa ALMEIDA, Giovana Goretti Feijó de; ARAÚJO JÚNIOR, Edson Modesto de. Estratégias de apropriação territorial na cultura tradicional dos indígenas Suruí em Rondônia-Brasil em tempos de Covid-19. Espaço Ameríndio, Porto Alegre, v. 15, n. 3, p. 71-90, set./dez. 2021. 
cultura local. Destaca-se que as fronteiras de um território não se limitam apenas a marcos geodésicos na separação de unidades espaciais, mas são igualmente de ordem simbólica e, no caso dos Suruís, também de ordem ambiental.

O respeito aos ciclos naturais é importante à conservação dos recursos ambientais necessários ao bem-estar, hábitos, tradições e crenças dos índios. Ao mesmo tempo, o respeito a esses ciclos é uma forma de desenvolvimento sustentável. Isso confirma que os Suruís são agentes naturais da sustentabilidade ambiental do território que ocupam, sendo um direito estabelecido na Constituição Federal do Brasil seu uso e apropriação de suas terras pelos indígenas, bem como o direito a ter respeitada suas tradições e crenças. Assim, somente os Suruís têm o direito legítimo a usufruir da riqueza de solos, rios e lagos existentes em suas terras.

Embora esteja previsto na Constituição do Brasil o direito à terra e crenças dos índios, a realidade da comunidade Suruí é outra, a ponto de essa comunidade vulnerável ter que criar formas para se proteger, como os guardiões da sustentabilidade, projeto que foi enviado ao Congresso Nacional pelas comunidades indígenas, mas ainda não foi aprovado. Em 2009, os povos Suruí enviaram uma carta ao Ministério da Justiça, Polícia Federal e Fundação Nacional do Índio (Funai), denunciando a invasão de suas terras por madeireiros e pediram providências dos órgãos responsáveis pela defesa da área.

"Não conseguimos entender quais são os verdadeiros motivos que impedem o poder público, com todas as suas leis e sua força policial, de resolver o problema da invasão madeireira na Terra Indígena Sete de Setembro de uma vez por todas", diz um dos trechos do referido documento (WM, 2021). Nesse documento formal, a comunidade indígena relata que é refém dos madeireiros, sendo que a maioria dos Suruí se posicionou contrários à extração de madeira na reserva indígena (Suruí, 2015; WM, 2021). Isso quer dizer que os índios estão sendo obrigados a se manter na extração de madeira contra sua vontade, o que também vai contra o que está previsto na legislação brasileira que diz que todas as pessoas têm o direito de ir e vir.

A Convenção 169, da Organização Internacional do Trabalho, garante aos povos indígenas o direito de serem consultados de forma preventiva, informada e justa, ao compromisso que põe em perigo sua vida e das gerações presentes e futuras. Além disso, consta na Constituição Federal Brasileira o impedimento de expulsão forçada dos índios de seus territórios, incentivo de as terras locais serem integrais e inacessíveis, garantias de que os povos indígenas não serão deportados de suas terras por falsos avanços na expansão econômica que visam o enriquecimento de determinados grupos agroindustriais em detrimento do meio ambiente e da vida presente e futura para as gerações vindouras. No entanto, o exercício e a manutenção de direitos legítimos previstos na Carta Magna do país não estão sendo respeitados, sendo uma luta contínua para praticamente todos os povos indígenas do Brasil essa legitimidade do uso de terras e o respeito das suas 
tradições. Mesmo nas terras que já estão devidamente demarcadas por lei, há constantemente a preocupação com projetos de lei ou medidas provisórias que privam os povos indígenas dos direitos garantidos pela Constituição Federal. Essa realidade de invasões às terras indígenas tem se intensificado em 2019 e 2020, época em que o Covid-19 tem se proliferado.

As notícias sobre a pandemia de Covid-19 são devastadoras e nas comunidades indígenas têm sido brutal sua devastação, visto que essas comunidades são mais frágeis em termos de saúde. Se um surto de sarampo, em 1960, quase extinguiu o povo Suruí, a Covid-19 pode ser o fator de extinção de um povo inteiro se não houver cuidados para que isso não se torne real. Esses cuidados não se dirigem apenas à saúde e vacinação, mas igualmente para que esses povos tenham seus direitos garantidos quanto ao uso e apropriação de suas terras e o direito a terem sua cultura tradicional respeitada.

\section{Cultura tradicional}

Rondônia possuía 43 terras indígenas, das quais 20 estão homologadas - o restante depende da identificação e demarcação do governo federal. Essas terras abrigam pelo menos 60 povos indígenas, incluindo 15 pessoas em isolamento voluntário (Ferreira, 2017), resultando em uma população tradicional de cerca de 15 mil habitantes (CIMI, 2015; Ferreira, 2017). A não-demarcação de terras indígenas representa um risco para a segurança dos povos indígenas que ali vivem e que, constantemente, estão à mercê dos ataques de mineiros, madeireiros, caçadores, proprietários de terras e outros invasores. Muitos indígenas têm se deslocado devido a essa insegurança. O processo migratório desordenado de povos indígenas avançou em países que abrigam várias etnias indígenas legítimas em solo brasileiro. Porém, essa migração ocorreu com grande resistência dessas comunidades.

A cultura tradicional do povo indígena dos Suruí está localizada nos Estados de Mato Grosso e Rondônia. Os Suruís são um grupo indígena brasileiro que se autodenominam Paiter, que na língua Tupi Mondé significa "gente de verdade, nós mesmos". A população de Paiter Suruí está dividida em quatro clãs patrilineares: Gabgir, simbolizado pelo fundo amarelo; Gameps, simbolizado pela vespa preta; Makór, representado por Taquara; e Kaban, que se refere à fruta doce. A terra indígena Sete de Setembro, em que estão localizados os Suruí, possui extensão territorial de 248.146.921 hectares e é onde vive a maioria dos Paiter, 215 famílias. Um trecho desta terra fica próximo à rodovia BR-364, ligando Kujawa a Porto Velho. As aldeias nessa região são chamadas de linhas desde à colonização de Rondônia que se deu em formato de espinha. Naquela época as estradas secundárias foram identificadas por linhas e números. Assim, as aldeias Suruí foram divididas nas linhas 7 a 12 e 14 (ISA, 2003). 
Desde 1960, a população Suruí vem sendo assolada por doenças, como, por exemplo, o sarampo que matou cerca de 300 pessoas na época (ISA, 2003). Embora as doenças do homem branco tenham ameaçado a sobrevivência dessa população, houve taxas de crescimento populacional significativas desde 1975: de 250 em 1975 para 450 em 1989; para 840 em 2000 (PARMSRN, 2010), correspondendo à taxa de 80\% em 1975 e 1988; e $87 \%$ entre 1988 e 1999 . No período de 1999-2010 essa taxa aumentou para uma média de $20 \%$ ao ano devido as ações de saúde e higiene promovidas, desde 1988, por associações locais com o apoio de agências internacionais e pela atuação do Fundo Nacional de Saúde / Casa de Apoio à Saúde do Índio (FUNASA / CASAI). De 1.231 pessoas em 2010, a população de Suruí aumentou para 1.241 em 2011 - 647 homens e 694 mulheres (CASAI, 2011 ). Além disso, em termos de idade, as crianças entre 0 e 12 anos constituem a maioria da população.

Dez anos depois do surto do sarampo que quase extinguiu a comunidade Suruí, a população é afetada pelo Covid-19. Dados da Secretaria Nacional de Saúde (SESAU), Distrito Sanitário Especial Indígena (DSEI) e o SUS confirmaram que 204 indígenas de Suruí e 156 índios de Cinta Larga testaram positivo com o novo coronavírus. O Conselho de Missionários Locais (CIMI) afirmou que a pandemia pode ter consequências mais graves para os povos indígenas, pois eles são mais suscetíveis ao vírus, principalmente, às infecções respiratórias, como a Covid-19. A morte da população local dos Suruí, especialmente os idosos, ameaça línguas, costumes e feriados tradicionais que não podem ser salvos. Trata-se de realidades que têm gerado insegurança para esses povos e causado uma dupla preocupação: dos índios como pedintes aos tribunais brasileiros de um direito de uso e apropriação territorial que lhes é legítimo pela Constituição Federal e da abertura que o prolongamento da homologação dessas terras gera para a legalização de terras obtidas por meio de invasões. Isso quer dizer que o direito indígena não está sendo cumprido legalmente, estendendo-se essa situação às demais comunidades marginalizadas do Brasil e América Latina.

\section{Resultados}

À vista do exposto, observaram-se estratégias na apropriação territorial em terras de culturas tradicionais, como a dos índios Suruí, em Rondônia, Brasil, durante a pandemia de Covid-19. Uma delas é a ampliação dos conflitos entre os atores sociais, que se valem da pandemia como um agente invisível para contribuir para a extinção de uma dada cultura tradicional. Neste sentido, conforme a Covid-19 vai se espalhando em comunidades vulneráveis, os invasores ampliam a ocupação ilegal das terras indígenas. Essa realidade pode gerar problemas para a cultura dos Suruís e para o meio ambiente. A extinção de culturas tradicionais antigas pode gerar uma insustentabilidade ambiental, impactando a biodiversidade de florestas, 
tais como as da Amazônia. Nesse sentido, pode-se pensar nessas culturas como agentes naturais do meio ambiente, sendo necessárias para a preservação de recursos naturais. Desta forma, os povos indígenas, como os Suruís, são agentes estratégicos do desenvolvimento sustentável, porém, informalmente. Ao não priorizar a vacinação desses povos contra a pandemia de Covid-19, planeja-se, conscientemente ou não, o extermínio da cultura indígena.

Trata-se ainda de perceber o conflito territorial por meio de múltiplas invasões, como tem acontecido nas terras dos Suruís demarcadas e homologadas legalmente, como um confronto político que negligencia o que está posto na Carta Magna do país. Essa situação expõe o desrespeito às leis do país e às pluralidades culturais do Brasil e América Latina. No contexto dos conflitos entre os atores sociais há três tipos de destruição: uma ligada diretamente às comunidades tradicionais; outra, indiretamente vinculada aos descasos com os recursos naturais do planeta e outra relacionada ao apagamento de culturas tradicionais.

Outro fator que tem sido uma estratégia na apropriação territorial de culturas tradicionais é a transformação forçada dessas culturas aos espaços urbanizados (cidades). Os indígenas precisam se sustentar economicamente e, para isso, a venda de seus artesanatos, por exemplo, ocorre na cidade. Ao conviver com os não-indígenas, os Suruís se transformam culturalmente e impactam suas identidades e representações sociais, o que pode levar a uma cultura híbrida (entre tradicional e urbana). Isso acontece quando elementos da cultura Ocidental se misturam com elementos da cultura tradicional, fundindo ambas as culturas. Essa fusão pode, com o tempo, levar à extinção de identidade, memórias e narrativas indígenas. As invasões e a pandemia vigente contribuem duplamente para novas lutas dessas comunidades vulneráveis, incluindo o direito de manter viva sua cultura original.

Assim, os invasores encontram na Covid-19 mais um aliado contra as culturas tradicionais locais, enfraquecendo os atores dessas comunidades, como os idosos que são responsáveis por passar sua cultura para as próximas gerações. Isso pode levar ao apagamento da identidade dessas culturas e até à sua extinção, estendendo-se essa preocupação aos crescentes óbitos indígenas; apagamento de sua história e suas memórias, que foram passadas oralmente por seus ancestrais aos mais idosos. Como a Covid-19 tem atingido os mais idosos, está a se falar de um processo que promove também o apagamento de territorialidades indígenas estabelecidas num determinado espaço de forma lenta e progressiva. Salienta-se que a memória e a história de uma cultural podem se transformar, estrategicamente e de forma planejada, numa marca territorial que se configura a partir da experiência singular dessas comunidades no território.

Investigou-se o caso dos índios Suruí, no Brasil, mas pode ser o caso de outras culturas locais minoritárias, como ribeirinhos e caiçaras. Sem cuidados de saúde e higiene específicos contra o coronavírus, os índios tendem a se tornar ainda mais frágeis, não podendo combater 0 desmatamento em seus territórios. Para se ter uma ideia desse cenário, em ALMEIDA, Giovana Goretti Feijó de; ARAÚJO JÚNIOR, Edson Modesto de. Estratégias de apropriação territorial na cultura tradicional dos indígenas Suruí em Rondônia-Brasil em tempos de Covid-19. Espaço Ameríndio, Porto Alegre, v. 15, n. 3, p. 71-90, set./dez. 2021. 
Caripun, Rondônia, a vegetação foi devastada em $7,97 \mathrm{~km}^{2}(2,09 \%)$ entre agosto de 2019 e setembro de 2020, período em que a pandemia Covid-19 estava no auge da contaminação.

Por fim, a pandemia força um processo migratório desordenado e imposto aos indígenas que se veem desapropriados das terras de seus antepassados, sendo justificada essa desapropriação como medida de saúde. Há um embate simbólico entre as territorialidades dos atores sociais por meio do discurso estratégico divulgado pela mídia em favor do desenvolvimento econômico que tem ultrapassado as fronteiras do país. Isso fez com que ONGs internacionais se voltassem ao contexto brasileiro dessas comunidades que estão em vias de extinção se nenhuma medida mais assertativa for tomada pelas governanças envolvidas no contexto das culturas tradicionais do Brasil. Devido à relação que esses povos têm com a natureza, física e simbolicamente (Godelier, 1984) torna-se estratégico atacar os territórios, coibindo-os de manter seu modo de subsistência como forma de expulsá-los de suas terras legitimadas pela Constituição do país. Quando não conseguem desta forma, outra estratégia, menos invasiva, é a demora na vacinação de um povo que é frágil por natureza ao coronavírus.

À vista do exposto, ficam evidenciados alguns tipos de estratégias que podem levar à extinção de comunidades tradicionais: atraso nas vacinas dos indígenas enquanto grupos prioritários; confronto simbólico e físico que pode ampliar os casos de Covid-19 na comunidade indígena; morte dos indígenas devido a pandemia, principalmente, dos idosos, fazendo com que parte de sua cultura também morra já que não será repassada às gerações futuras; extinção da identidade indígena devido à transformação de sua cultura ao longo dos anos, em especial, em tempos pandêmicos; a nãodemarcação de terra indígenas tendo a pandemia como justificativa; e a migração indígena forçada, derivada de distintos fatores, incluindo a pandemia.

Do lado dos Suruís, a formação do grupo guardiões da sustentabilidade é uma estratégia para garantir os indígenas em suas terras que, porém, não evita a invasão e, tampouco, o confronto físico. Esse confronto pode ampliar ainda mais a pandemia em comunidades marginalizadas que possuem fragilidade de saúde maior do que da cultura Ocidental frente à Covid-19. Esse grupo revela três perspectivas: a) enquanto projeto de política pública indígena, confirmando que a cultura indígena teve que se apropriar das leis Ocidentais para reclamar seus direitos previstos na Constituição do país; b) os indígenas como agentes naturais da sustentabilidade ambiental, uma espécie de fiscais informais; e, c) a mistura de culturas, tradicional indígena e Ocidental, gerando o que se chamou de cultura híbrida, em que o espaço urbano tem transformado o indígena (os guardiões) a tal ponto de usarem nomenclaturas como sustentabilidade ao invés de mato e terem que fazer um projeto de cunho político para terem reconhecido o direito de constituírem formalmente o referido grupo.

\section{Conclusão}

ALMEIDA, Giovana Goretti Feijó de; ARAÚJO JÚNIOR, Edson Modesto de. Estratégias de apropriação territorial na cultura tradicional dos indígenas Suruí em Rondônia-Brasil em tempos de Covid-19. Espaço Ameríndio, Porto Alegre, v. 15, n. 3, p. 71-90, set./dez. 2021. 
A pandemia Covid-19 é uma realidade também nas culturas tradicionais, podendo se tornar mais agravada em comunidades vulneráveis. $\mathrm{Na}$ luta contra os invasores de terras indígenas, muitos indígenas tem sido assassinados e a devastação de áreas ambientais tem sido ampliada. Além disso, a extinção de comunidades tradicionais tem levado ao apagamento da identidade territorial de etnias indígenas. Essa extinção tem ocorrido também pela ausência de cuidados de saúde, higiene e vacinação em comunidades indígenas, podendo a pandemia ser uma das causas para que essas comunidades vulneráveis sejam extintas.

O objetivo foi atendido na medida em que permitiu a compreensão de estratégias na apropriação territorial em terras de culturas tradicionais, como a dos índios Suruí, em Rondônia, Brasil. O estudo permitiu compreender os tipos de conflitos em território Suruí, o perfil territorial dessas terras e a própria cultura Suruí, bem como o entendimento do lugar da cultura tradicional e do pluralismo cultural na sociedade contemporânea como um agente ambiental estratégico necessário à manutenção dos recursos naturais do planeta.

Os resultados apontaram para um conjunto de conflitos que tem assolado as terras indígenas, indo além das invasões de madeireiros, incluindo os problemas oriundos da Covid-19 e da luta para tornar os povos indígenas grupos prioritários na vacinação contra o coronavírus. Encontrouse que a Constituição Federal apresenta lacunas que permitem que as terras indígenas invadidas possam ser homologadas pelos invasores. Essa situação coloca em risco as territorialidades dos indígenas, bem com a existência de sua cultura tradicional. A realidade dos Suruí é similar a de outras comunidades vulneráveis, podendo este estudo ser generalizado a outras culturas tradicionais da América Latina. Além disso, foram evidenciadas estratégias em que a Covid-19 pode ser sido utilizada como acelerador da extinção de comunidades tradicionais.

As contribuições da pesquisa para a ciência remetem ao aprofundamento da temática sobre as culturas tradicionais no Brasil e na América Latina, e ao prejuízo da ausência de diversidade das culturas tradicionais à sociedade. Para o povo Suruí, a contribuição se dirige ao fortalecimento de sua cultura como importantes agentes naturais de manutenção da sustentabilidade ambiental, convertendo a informalidade desse papel na sociedade para um papel formal e necessário. Para os planejadores de políticas públicas, destacam-se os insights quanto à saúde e existência dessas comunidades, sendo uma riqueza cultural-ambiental valiosa que pode atuar na preservação do meio ambiente. Além disso, há a necessidade de se concentrar em políticas públicas contemporâneas que erradiquem a fome, a mortalidade infantil e a pobreza extrema em que vivem as comunidades tradicionais.

As limitações da pesquisa se dirigem à investigação de apenas uma etnia indígena, os Suruí, localizada em Rondônia, Brasil. Desta forma, como sugestão para pesquisas futuras, seria importante investigar outras culturas tradicionais indígenas daquela região e as pautas das agendas de políticas

ALMEIDA, Giovana Goretti Feijó de; ARAÚJO JÚNIOR, Edson Modesto de. Estratégias de apropriação territorial na cultura tradicional dos indígenas Suruí em Rondônia-Brasil em tempos de Covid-19. Espaço Ameríndio, Porto Alegre, v. 15, n. 3, p. 71-90, set./dez. 2021. 
Espaço Ameríndio

de saúde pública no que tange às epidemias e pandemias de comunidades tradicionais.

A conclusão reitera que as estratégias de apropriação territorial em terras indígenas foram ampliadas, dando indícios da existência de um processo de apagamento da identidade territorial dos índios na América Latina, podendo ser ampliada essa situação pela pandemia vigente. Isso ocorre porque quando se apaga ou se está no processo de apagamento de uma identidade territorial, tem-se relações de dominador e dominado, gerando graves conflitos territoriais, simbólico-culturais e, neste caso, também ambientais. É uma situação em que ambas as partes (dominador e dominado) valem-se de estratégias para avançar em suas intenções. 
Espaço Ameríndio

\section{Referências bibliográficas}

ALMEIDA, A. W. B. Amazônia: a dimensão política dos conhecimentos tradicionais. In: Acselrad, H. (Org). Conflitos Ambientais no Brasil. Rio de Janeiro: Ed. Reúne Dumaró, 2004, p. 37-56.

ALMEIDA, G. G. F. Marca territorial como produto cultural no âmbito do Desenvolvimento Regional: o caso de Porto Alegre, RS, Brasil. 2018. Tese Doutorado em Desenvolvimento Regional, Universidade de Santa Cruz do Sul, Brasil, 2018.

ARAUJO JÚNIOR, E. M. Consumo de experiência turístico-religiosa na construção de territorialidades na Terra Santa. 2020. Tese Doutorado em Desenvolvimento Regional, Universidade de Santa Cruz do Sul, Brasil, 2020.

BRASIL DE FATO. Sob ameaça de morte, lideranças indígenas lutam para proteger floresta no Maranhão. 2020. Disponível em: https://www.brasildefato.com.br/2020/09/01/sob-ameaca-de-morte-liderancas-indigenaslutam-para-proteger-floresta-no-maranhao. Acesso em: 10 jan. 2021.

BRASIL. Constituição da República Federativa do Brasil de 1988. Disponível em: http://www.planalto.gov.br/ccivil_03/constituicao/constituicao.htm. Acesso em abril de 2021.

BUSTAMANTE PATIÑO, B.; HERRERO OLARTE, S. La clase dominante como determinante de la forma de Quito. Bitácora Urbano Territorial, v. 27, n. 3, p. 81-90, 2017.

CALDERÓN, A. M. Adaptación y exclusión: versiones del derecho al territorio. El caso de Pensilvania, Caldas. Bitácora Urbano Territorial, v. 25, n. 2, p. 59-66, 2015.

CARVALHO, J. J. O lugar da cultura tradicional na sociedade moderna. Série Antropologia, n. 77. Universidade de Brasília. 1989. Disponível em: http://www.dan.unb.br/images/doc/serie77.pdf. Acesso em: 20 mar. 2020.

CASTRO, E. (2000). Território, Biodiversidade e Saberes de Populações Tradicionais. In: Diegues, A. C. (Org.). Etnoconservação: novos rumos para a conservação da natureza. São Paulo: Ed. HUCITEC, 2000, p. 165-182.

CEDC. Coordenadoria Estadual da Defesa Civil. Marco de Sendai para Redução de Riscos e Desastres. 2015. Disponível em: http://www.defesacivil.pr.gov.br/Pagina/Marco-deSendai-para-Reducao-de-Riscos-e-Desastres.

CUNHA, M. C.; Almeida, M. Enciclopédia da Floresta. Companhia das Letras, São Paulo, 2002.

DIEGUES, A. C. S. $O$ mito moderno da natureza intocada. Editora HUCITEC: São Paulo, 1998.

ALMEIDA, Giovana Goretti Feijó de; ARAÚjO JÚNIOR, Edson Modesto de. Estratégias de apropriação territorial na cultura tradicional dos indígenas Suruí em Rondônia-Brasil em tempos de Covid-19. Espaço Ameríndio, Porto Alegre, v. 15, n. 3, p. 71-90, set./dez. 2021. 
Espaço Ameríndio

DIEGUES, A. C. et al. Biodiversidade e comunidades tradicionais no Brasil. Ministério do Meio Ambiente, Recursos Hídricos e da Amazônia Legal, Cobio-Coordenadoria da Biodiversidade Nupaub-Núcleo de Pesquisas sobre Populações Humanas e Áreas Úmidas Brasileiras, Universidade de São Paulo, Brasil, 2000.

DOMINGO, S. V.; CASTEDO MARIA, E. Análise do comportamento socioambiental terena por meio de marcadores espaço-temporais: uma contribuição para a conservação da cultura. Interações, v. 18, n. 1, p. 59-73, 2017.

DOTTO, J. Indígenas recusam vacina contra a Covid-19 em Estrela Velha. Postagem em: 27/01/2021, às 19h58, no Portal Globo.com. 2021. Disponível em: https://g1.globo.com/rs/rio-grande-do-sul/noticia/2021/01/27/indigenas-recusam-vacinacontra-a-covid-19-em-estrela-velha.ghtml. Acesso em: mar. 2021.

FERNÁNDEZ-LABBÉ, J. El territorio como espacio contradictorio: promesas y conflitos en torno a la actividad extractiva em Ecuador, Colombia, Perú y Chile. EURE, v. 46, n. 137, p. 225-246, 2020.

FERREIRA, I. A. Povos indígenas de Rondônia: rumo aos 518 anos de resistência. 2017. https://www.alainet.org/pt/articulo/189961. Acesso em: abr. 2020.

FUNAI. Canal YouTube Funai - Fundação Nacional do Índio (oficial). Povos Indígenas:

Guardiões da Sustentabilidade, Castanha Suruí. YouTube. 2018. Acesso: 23 jan. 2021. https://www.youtube.com/watch?v=qYLxQtePu7o

GARCÍA GUALDA, S. M. Urbanización y municipalización en territorio indígena. Bitácora Urbano Territorial, $v .31$, n. 2, p. 131-142, 2021.

GARCÍA-JEREZ, F. A. El extractivismo urbano y su giro ecoterritorial. Una mirada desde América Latina. Bitácora Urbano Territorial, v. 29, n. 2, p. 21-28, 2019.

GLOBAL WITNESS. Relatório anual Defending Tomorrow. 2020. Disponível em: https://www.brasildefato.com.br/2020/09/01/sob-ameaca-de-morte-liderancas-indigenaslutam-para-proteger-floresta-no-maranhao. Acesso em: 10 jan 2021.

GODELIER, M. L'idéel et le matériel. Paris, Fayard, 1984.

GUEDES, A. D. Lutas por terra e território, desterritorialização e território como forma social. Rev. Bras. Estud. Urbanos Reg., v. 18, n. 1, p. 23-39, 2016.

HAESBAERT, R. Território, Cultura e Des-territorialização, In: Rosendahl, Z; Corrêa, R.L, Religião, Identidade e Território. Rio de Janeiro: EdUERJ, 1999.

ISA. Instituto Socioambiental. Índios isolados e de recente contato relatam ameaças de morte e invasão de territórios. 2018. Disponível em: https://www.socioambiental.org/pt-

ALMEIDA, Giovana Goretti Feijó de; ARAÚJO JÚNIOR, Edson Modesto de. Estratégias de apropriação territorial na cultura tradicional dos indígenas Suruí em Rondônia-Brasil em tempos de Covid-19. Espaço Ameríndio, Porto Alegre, v. 15, n. 3, p. 71-90, set./dez. 2021. 
$\mathrm{br} /$ noticias-socioambientais/indios-isolados-e-de-recente-contato-relatam-ameacas-demorte-e-invasao-de-territorios. Acesso em: 30 abr. 2021.

LEITE, A. F., MONIÉ, F. A geopolítica e a análise dos conflitos territoriais locais nas cidades portuárias. Anais... Congresso Brasileiro de Geografia Política, Geopolítica e Gestão do Território, p. 1070-1081, 2014.

LEVI-STRAUSS, C. A ciência do concreto. In: Lévi-Strauss, C., Pellegrini, T. O Pensamento Selvagem. São Paulo: Companhia Editora Nacional, 1976.

LUCIANO, R. R. F. et al. Políticas públicas para indígenas: da educação básica ao ensino superior. Interfaces da Educação, v. 11, n. 32, p. 571- 605, 2020.

MARCILINO, O. T.; TOMAZ, V. S. Localização, orientação e representação espacial como expressão de territorialidades indígenas. Tellus, maio/ago, v. 42, p. 181-215, 2020.

MARÉCHAL, C. et al. Transformações sociais e (re)territorialização warao no Brasil: a trajetória de uma família frente à pandemia de Covid-19. Espaço Ameríndio, 14(2), 46-87, jul./dez, 2020.

MENEZES, A. L. T. et al. Encontros interculturais entre um indígena Kaingang e não indígenas: enlaces em um pensar perspectivista e sincrônico. Tellus, jan./abr., n. 41, p. 129$146,2020$.

MONTERO GRANIELA, A. Economías creativas en centros históricos. La Habana Vieja. Bitácora Urbano Territorial, v. 31, n. 2, p. 189-202, 2021.

NASCIMENTO SILVA, Elis do. Projetos hidrelétricos em territórios indígenas no sul do Brasil no contexto da ditadura civil-militar: uma análise a partir do acervo de Silvio Coelho dos Santos. Espaço Ameríndio, Porto Alegre, v. 12, n. 2, p. 421-457, jul./dez. 2018.

NICOLETTI, M. A., NÚÑEZ, P. G. Desarrollo y sentidos del territorio norpatagónico. Bitácora Urbano Territorial, v. 29, n. 2, p. 169-178, 2019.

OPAS. Organização Pan-Americana de Saúde. 2021. Disponível em: https://www.paho. org/pt/brasil

OSORIO CAMPILLO, H. A. et al. Territorios y migraciones: Territorialidades en transformación. Bitácora Urbano Territorial, v. 25, n. 1, p. 113-122, 2015.

OZOUF, D. Um sentido global do Lugar. In: ARANTES, O. (Org). O Espaço da Diferença. Campinas: Papirus, 1976.

PARMSRN. Plano de Ação Participativo para o Desenvolvimento de uma Economia Racional e de Manejo Sustentável dos Recursos Naturais da Terra Indígena Sete de Setembro. Documento interno ao Projeto REDD+ Suruí. 2010. 
PEREIRA, A. M. A riqueza Sociolinguística e Cultural dos Povos indígenas de Rondônia. Anais... SIELP, v. 1, n. 1, Uberlândia: EDUFU, 2011.

PERIUS, E. Indígenas Kaingang em Santa Maria: etnogênese e espaço urbano. Espaço Ameríndio, Porto Alegre, v. 14, n. 2, p. 109-140, jul./dez. 2020.

PRECIADO TRUJILLO, E. A. La territorialidad en el proceso de la migración: Un acercamiento a la cartografía de proximidad. Bitácora Urbano Territorial, v. 27, n. 3, p. 149-154, 2017.

RADICCHI, M. R. Visibilidade do indígena em situação urbana nas microrregiões do Estado do Amazonas a partir do censo demográfico. Espaço Ameríndio, v. 14, n. 2, p. 88-108, jul./dez. 2020.

RAFFESTIN, C. Por uma geografia do poder. Editora Ática, São Paulo, 1993.

RAMIREZ, C. M. Transformaciones territoriales: una categoría de análisis para explicar las dinámicas de conformación territorial. Urbano Territorial Bitácora, v. 26, n. 2, p. 113-120, 2016.

RODRÍGUEZ, L. Y. et al. El lugar de la memoria: enseñanza del urbanismo. Bitácora Urbano Territorial, v. 29, n. 1, p. 171-180, 2019.

SANTILLI, J. A biodiversidade de as comunidades tradicionais. In: Besunsan, N. (Org.) Seria Melhor Ladrilhar? Biodiversidade como, para que, porquê. Brasília: Editora Universidade de Brasília: Instituto Socioambiental, 2002.

SANTOS, J. A. et al. Reescrevendo a história sob uma perspectiva indígena: a desconstrução da figura do "desbravador" no oeste de Santa Catarina. Interfaces da Educação, v. 11, n. 33, p. 223-244, 2020.

SAQUET, M. A. A descoberta do território e outras premissas do desenvolvimento territorial. Rev. Bras. Estud. Urbanos Reg., v. 20, n. 3, p. 479-505, set-dez., 2018.

SIEGERT, A. et al. Territorios tradicionales y aprovechamientos económicos en Urabá, Colombia. Ordenamientos productivos en ecosistemas de humedales. Bitácora Urbano Territorial, v. 28, n. 3, p. 171-180, 2018.

SURUÍ, R. L. A importância da alimentação tradicional na cultura do povo Paiter da Aldeia Lapetanha, Cacoal, Rondônia. 2015. http://www.deinter.unir.br/uploads/87443803/

tcc/2015 Renato Labiway Surui.pdf. Acesso em: abr. 2020.

TAMAGNO, L. E.; MAIDANA, C. A. Grandes urbes y nuevas visibilidades de la diversidade. Rev. Bras. Estud. Urbanos Reg., v. 13, n. 1, p. 51-61, 2011. 
TORRES TOVAR, C. A. Conflictos territoriales y acuerdos de paz en Colombia. Bitácora Urbano Territorial, v. 26, n. 2, p. 7-10, 2016.

VÁZQUEZ-HONORATO, L. A., Salazar-Martinez, B. lilia, \& García-Medina, K. M. Evaluación de un modelo urbano nuevo. Santiago el Pinar, México, 1999-2013. Bitácora Urbano Territorial, v. 29, n. 2, p. 71-80, 2019.

WM. Site de notícias Wayback Machine. Índios Suruí de Rondônia denunciam a invasão de suas terras por madeireiros: Ministério Público Federal. 2010. https://bit.ly/3xaYYFg. Acesso em: 30 jan. 2021.

YIN, R. K. Estudo de caso: planejamento e métodos. Porto Alegre: Bookman, 2015.

Recebido em: 13/06/2021 * Aprovado em: 09/08/2021 * Publicado em: 23/12/2021 